\title{
Correction to: Is It a Single Anastomosis Gastric Bypass or Is It a Single Anastomosis Biliopancreatic Diversion?
}

Michel Gagner ${ }^{1,2}$

Published online: 25 July 2018

(C) Springer Science+Business Media, LLC, part of Springer Nature 2018

\section{Correction to: Obesity Surgery \\ https://doi.org/10.1007/s11695-018-3386-6}

Due to errors during the production process, several corrections to this article were excluded in the published article. The following bolded text is correct.

Paragraph 1:

I have been asked to review the paper entitled "One Anastomosis (Mini) Gastric Bypass is now an Established Bariatric Procedure: A Systematic Review of 12,807 patients," by Parmar and Mahawar [1]. Yes, the procedure has been endorsed by IFSO recently, which is contrary to current practice in North America, and ASMBS has decided not to endorse the procedure, even though it has reviewed the same literature and body of evidence [2]. A decision based on unknown...

Paragraph 5, last sentence:

In well-studied cohorts, mineral and vitamin deficiencies after Roux-en-Y gastric bypass alterations are seen up to 33-55\%, to $75 \%$ in non-compliant patients [18]; hence, it should be worse with SAGB.

Reference 1:

1. Parmar, C.D. \& Mahawar, K.K. "One Anastomosis (Mini) Gastric Bypass Is Now an Established Bariatric Procedure: a Systematic Review of 12,807 Patients" Obes Surg (2018). https://doi.org/10.1007/s11695-018-3382-x

Reference 2:

2. Parikh M, Eisenberg D, Johnson J, El-Chaar M; American Society for Metabolic and Bariatric Surgery Clinical Issues Committee. American Society for Metabolic and Bariatric Surgery review of the literature on one-anastomosis gastric bypass. Surg Obes Relat Dis. 2018. May 9 pii: S 15507289(18): 30240-5. (ePub).

The online version of the original article can be found at https://oi.org/ 10.1007/s11695-018-3386-6

Michel Gagner

gagner.michel@gmail.com

1 Herbert Wertheim School of Medicine, FIU, Miami, FL, USA

2 Hôpital du Sacre Coeur, Montreal, Canada 